\title{
Medievalista
}

\section{Manuscritos hebraicos em Portugal}

Hebrew manuscripts in Portugal

\section{Tiago Moita}

\section{OpenEdition}

\section{Journals}

Edição electrónica

URL: http://journals.openedition.org/medievalista/1350

DOI: 10.4000/medievalista.1350

ISSN: 1646-740X

\section{Editora}

Instituto de Estudos Medievais - FCSH-UNL

\section{Refêrencia eletrónica}

Tiago Moita, « Manuscritos hebraicos em Portugal », Medievalista [Online], 22 | 2017, posto online no dia 01 dezembro 2017, consultado no dia 19 abril 2019. URL : http://journals.openedition.org/ medievalista/1350 ; DOI : 10.4000/medievalista.1350

(C) IEM 
Título / Title: Manuscritos hebraicos em Portugal / Hebrew manuscripts in Portugal Autor(es) / Author(s): Tiago Moita

Universidade / University: Universidade de Lisboa

Faculdade e Departamento / Unidade de Investigação - Faculty and Department Research Center: Faculdade de Letras, Artis - Instituto de História de Arte

Código Postal / Postcode: 1600-214

Cidade / City: Lisboa

País / Country: Portugal

Email Institucional / Institutional email: tiago-moita@campus.ul.pt

Fonte: Medievalista [Em linha]. Direc. Bernardo Vasconcelos e Sousa. Lisboa: IEM.

Disponível em:

http://www2.fcsh.unl.pt/iem/medievalista/MEDIEVALISTA22/moita2206.html

ISSN: 1646-740X

Data recepção do artigo / Received for publication: 4 de Fevereiro de 2017

Data aceitação do artigo / Accepted in revised form: 11 de Maio de 2017 


\section{Resumo}

Este artigo realiza o primeiro inventário global dos manuscritos hebraicos existentes nas bibliotecas públicas e arquivos estatais portugueses. O inventário compreende a identificação e localização dos manuscritos, apresentados de acordo com um critério temático, além da indicação da sua origem e data provável de produção, tarefa realizada com base numa análise codicológica e paleográfica dos volumes. As circunstâncias da aquisição ou entrada dos manuscritos nas bibliotecas são também avaliadas. Em muitos casos, os resultados obtidos permitem atualizar a informação existente sobre estes manuscritos nos catálogos das bibliotecas que os guardam.

Palavras-chave: manuscritos hebraicos; inventário; bibliotecas; codicologia; Portugal

\section{Abstract}

This paper makes the first comprehensive inventory of Hebrew manuscripts in public libraries and state archives in Portugal. The inventory includes the identification and location of the manuscripts and presentation according to their contents; following a thorough codicological and paleographical analysis, their origin and probable date of production is also discussed. The circumstances of acquisition or entry of the volumes into the libraries are also considered. In many cases, the results obtained allow the update of the existing information about these manuscripts in the catalogs of the libraries where the volumes are held.

Keywords: Hebrew manuscripts; inventory; libraries; codicology; Portugal 


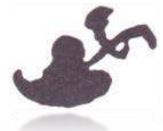

\section{Manuscritos hebraicos em Portugal / Hebrew manuscripts in Portugal}

\author{
Tiago Moita
}

A António Augusto Tavares in memoriam

No decorrer da minha investigação de doutoramento, dedicada ao livro hebraico português na Idade Média $^{1}$, constatei que o conjunto de manuscritos hebraicos existentes nas bibliotecas públicas e arquivos estatais portugueses carecia de um inventário global, sendo desconhecido o número real dos remanescentes conservados no país - situação que contrasta, por exemplo, com os manuscritos árabes, melhor estudados $^{2}$. Do mesmo modo, verifiquei também que se alguns manuscritos, porventura os mais luxuosos, haviam recebido particular atenção da comunidade científica, nacional e internacional, com estudos significativos, a maior parte deste rico património permanecia vaga e defeituosamente descrito nos catálogos de manuscritos das bibliotecas portuguesas. Por forma a colmatar esta lacuna, procurei realizar na investigação referida um inventário dos manuscritos e fragmentos hebraicos conservados em Portugal, independentemente da origem da sua produção, elaborando para cada espécime identificado uma ficha analítica que compreende, entre outros aspetos, os dados codicológicos e históricos que então pude recolher ${ }^{3}$. O corpus reunido compreende um total de vinte e três manuscritos e fragmentos hebraicos guardados nas bibliotecas e arquivos portugueses, quase todos produzidos na Península Ibérica entre os séculos XIV e XV, mas também noutros países da Europa (sobretudo nas áreas

\footnotetext{
${ }^{1}$ MOITA, Tiago - O livro hebraico português na Idade Média. Do Sefer he-Aruk de Seia (1284-85) aos manuscritos iluminados tardo-medievais da Escola de Lisboa e aos primeiros incunábulos. Lisboa: Faculdade de Letras da Universidade de Lisboa, 2017. Tese de Doutoramento.

2 SIDARUS, Adel - "Manuscritos árabes em Portugal”. Estudos Orientais 2 (1991), pp. 117-126.

${ }^{3}$ Estas fichas analíticas encontram-se em Apêndice no volume 2 da dissertação, ns. 61-83.
} 
geoculturais asquenazita e italiana) e do Médio Oriente ${ }^{4}$. Estes volumes encontram-se guardados nas seguintes bibliotecas e arquivos nacionais: Biblioteca Pública Municipal do Porto, Biblioteca Geral da Universidade de Coimbra, Biblioteca Nacional de Portugal, Biblioteca Pública de Évora, Biblioteca do Paço Ducal de Vila Viçosa, e Arquivo Nacional da Torre do Tombo. Partindo da informação apurada, fundamentada na análise codicológica e paleográfica dos volumes, intento neste estudo sintetizar, atualizar e ampliar a informação biblioteconómica relativa aos manuscritos hebraicos conservados em Portugal, tendo em conta a sua origem, datação e conteúdo. Sempre que possível chamarei a atenção para a história dos manuscritos bem como para as circunstâncias da sua entrada nas bibliotecas portuguesas. Para o efeito, serão consideradas as informações históricas inscritas nos volumes por sucessivos proprietários ou outras informações relevantes. Para um entendimento mais imediato dos remanescentes optámos por distribuí-los de acordo com critérios temáticos.

\section{Bíblias}

A esmagadora maioria dos manuscritos hebraicos conservados nas bibliotecas e arquivos portugueses são códices bíblicos. Encontram-se quase todos em estado fragmentário, exceto duas Bíblias completas, de grande valor artístico, preservadas uma, em Lisboa, na Biblioteca Nacional de Portugal - a famosa Bíblia de Cervera (Ms. Iluminado 72) ${ }^{5}$, e outra em Coimbra, na Biblioteca Geral da Universidade de Coimbra - conhecida como

\footnotetext{
${ }^{4}$ Este inventário incide exclusivamente nos manuscritos e fragmentos hebraicos em forma de códice. $\mathrm{O}$ inventário não inclui os três rolos da Torá conservados nas bibliotecas e arquivos portugueses, nomeadamente, na Biblioteca Pública de Évora (adquirido por Frei Manuel do Cenáculo, em 1803, na Holanda) (Gaveta 8), na Biblioteca Pública e Arquivo Distrital de Ponta Delgada (a conhecida "Torá de Rabo de Peixe", encontrada numa gruta daquela localidade, na ilha de S. Miguel, em 1997, mas executada provavelmente em Marrocos no início do século XIX) (Cofre 270 Res), e no Arquivo Municipal da Covilhã (provavelmente do século XIX, descoberta recentemente, nos finais de 2016). Sobre a Torá que se encontra em Ponta Delgada, veja-se CARREIRA, José Nunes - "Torá de Rabo de Peixe". Cadmo. Revista do Instituto Oriental da Universidade de Lisboa 4-5 (1995), pp. 205-208. De fora deste inventário ficam também duas mezuzot, datáveis dos séculos XV-XVI, guardadas na Biblioteca Nacional de Portugal (Ms. 256, n. 43) e na Biblioteca Pública de Évora (Cod. CXXIV/2-48 d). Sobre a mezuzah de Évora, vejase BALLESTEROS, Carmen - "Mezuzah da Biblioteca Pública de Évora". A Cidade de Évora: Boletim de Cultura da Câmara Municipal (2 $2^{\mathrm{a}}$ Série) 2 (1996), pp. 285-296. SOALHEIRO, João - "124. Mezuzah". in AZEVEDO, Carlos A. Moreira (coord.) - Cristo, Fonte de Esperança (Catálogo da Exposição). Porto: Diocese do Porto, 2000, p. 216. Sobre a mezuzah da Biblioteca Nacional de Portugal, veja-se MUCZNIK, Lúcia Liba - Judaica. Nas coleções da Biblioteca Nacional de Portugal, Séculos XIII a XVIII. Lisboa: BNP, 2014, p. 45, n. 23. Esta mezuzah encontra-se disponível em http://purl.pt/27155 ${ }^{5}$ Disponível em http://purl.pt/23405
} 
Bíblia de Coimbra (Cofre 1) ${ }^{6}$. Estes dois manuscritos, com os vinte e quatro livros da Bíblia hebraica, tratados gramaticais diversos e texto massorético, foram estudados por investigadores portugueses em publicações recentes, para as quais remeto o leitor interesado na temática ${ }^{7}$. Em todo o caso, importa referir aqui que nenhum dos volumes referidos foi produzido em Portugal: a Bíblia de Cervera foi realizada, conforme o seu cólofon, em 1299-1300, em Cervera [del Río Alhama?]; a Bíblia de Coimbra, mais tardia, foi executada na segunda metade do século XV, em Sevilha ou Córdova. Os manuscritos deram entrada nas instituições portuguesas no começo do século XIX, comprados ambos na Holanda: a Bíblia de Cervera foi adquirida na cidade de Haia, em 1804, por indicação de António Ribeiro dos Santos (1745-1818), primeiro bibliotecário-mor da então Real Biblioteca Pública, hoje Biblioteca Nacional de Portugal; a Bíblia de Coimbra, por seu turno, foi obtida através do Doutor Manuel Pedro de Mello (1765-1833), decano da Faculdade de Matemáticas, para a Biblioteca da Universidade de Coimbra, dando entrada na livraria em 1857, depois de alguns anos esquecida nas estantes da secretaria daquela universidade.

Fora estas Bíblias completas, a massa dos manuscritos bíblicos hebraicos conservados em Portugal encontra-se em estado fragmentário, como disse, tendo sido encontrados na maioria dos casos no interior de encadernações de códices latinos ou portugueses (num caso isolado também na encadernação de um incunábulo hebraico de origem portuguesa) ${ }^{8}$. Em grande medida, os fragmentos identificados são provenientes de

\footnotetext{
${ }^{6}$ Disponível em http://webopac.sib.uc.pt/search S17*por?/cCofre+1/ccofre+1/1,5,5,E/1856 b1813600\&FF=ccofre+1\&1,1 $, 1,0 /$ indexsort $=-$

7 RAMOS, José Augusto; AFONSO, Luís Urbano; MOITA, Tiago - "A Bíblia de Cervera: um manuscrito sefardita iluminado?". Cadernos de Estudos Sefarditas 14 (2015), pp. 171-202. AFONSO, Luís Urbano; MOITA, Tiago; MATOS, Débora - "La Biblia de Coimbra y la «Escuela Andaluza» de iluminacíon hebraica". Archivo Español de Arte 88/349 (2015), pp. 53-68.

${ }^{8}$ A reutilização dos manuscritos sefarditas nas encadernações da maioria cristã depois da expulsão dos judeus da Península Ibérica no final do século XV parece ter sido uma prática comum. Sobre este assunto, e para o caso português, veja-se o nosso estudo MOITA, Tiago - "O livro hebraico português medieval: uma história de sobrevivência". in AFONSO, Luís Urbano; MIRANDA, Adelaide (ed.) - O livro e a iluminura judaica em Portugal no final da Idade Média. Lisboa: BNP, 2015, pp. 67-77 (especialmente pp. 69-71). Para outros casos, vejam-se as seguintes estudos: DEL BARCO, Javier; SANTOS, Inacio Panizo - "Fragmentos de incunables hebreos en documentos inquisitoriales del Tribunal de CalahorraLogroño". Huarte de San Juan. Geografía e Historia 17 (2010), pp 295-308. LEHNARDT, Andreas "Genizat Germania" - Hebrew and Aramaic Binding Fragments from Germany in Context. LeidenBoston: Brill, 2010. PERANI, Mauro - "Morte e rinascita dei manoscritti ebraici: il loro riuso come legature e la loro recente riscoperta". in CANETTI, Luigi; CAROLI, Martina; MORINI, Enrico;
} 
manuscritos sefarditas, produzidos em Espanha ou em Portugal; alguns remanescentes foram realizados em outras áreas geoculturais, na Europa e no Médio Oriente.

Comecemos pela Biblioteca Geral da Universidade de Coimbra. Na Caixa B 12, encontramos um fragmento do Deuteronómio (30,16 - 31,12), escrito com caracteres quadrados, de tipo asquenaze, com sinais vocálicos, e texto massorético nas margens (figura 1). $\mathrm{O}$ documento pertenceu a um manuscrito produzido em território alemão nos começos do século XIV, conforme se pode apurar pela tipologia paleográfica da sua escrita. Foi encontrado a servir à encadernação de um manuscrito latino, intitulado Aliqua adnotata in Manuale Nauarri (Ms. 1173), uma coletânea de comentários a alguns pontos apresentados no Enchiridon sive Manuale Confessarium et Poenitentium do famoso professor da Universidade de Coimbra, o jesuíta Martim Azpicuelta, também conhecido como Dr. Navarro 9 .

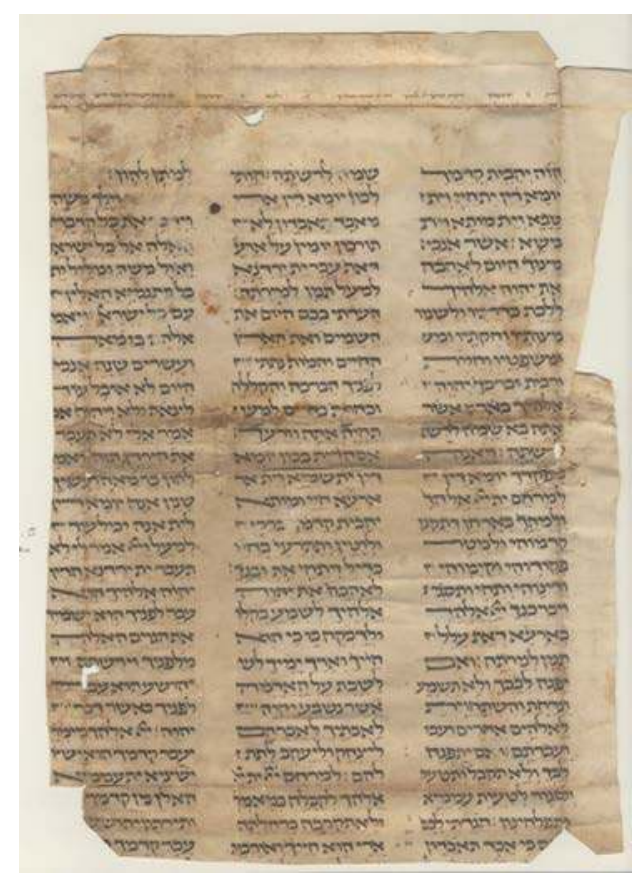

Figura 1 - Bíblia (fragmentos), Alemanha, século XIV. Coimbra, Biblioteca Geral da Universidade de Coimbra, Caixa B 12, fol. 1v (permissão para reprodução obtida pelo autor do artigo em 02/03/2017).

SAVIGNI, Raffaelle (ed.) - Studi di storia del cristianesimo. Per Alba Maria Orselli. Ravena: Longo Angelo, 2008, pp. 313-336.

${ }^{9}$ COIMBRA JUDAICA - Actas. Coimbra: Câmara Municipal de Coimbra, 2009, p. 257, n. 1.2. 
Proveniente também de um manuscrito realizado em território alemão, mas em data anterior, entre os finais do século XII ou começos do século XIII, encontra-se o fragmento do Primeiro Livro de Samuel (cap. 19) conservado na Biblioteca Pública de Évora (Cod. CXXV/2-14, n. 1). Escrito num tipo paleográfico de letra quadrada asquenazita, com vocalização, apresenta as margens muito aparadas e o texto severamente truncado, tendo sido encontrado no interior da encadernação de um livro antigo, não identificado. Em condições semelhantes foram descobertos nesta mesma instituição dois outros conjuntos de fragmentos bíblicos, ambos copiados num tipo paleográfico de letra quadrada sefardita, com vocalização, e desprovidos de massorá: um dos documentos contém partes do livro do Exodo (caps. 12-13) (Cod. CXXV/2-14, n. 3) (figura 2); o outro documento apresenta partes do Eclesiastes (caps. 8-9) (Cod. CXXV/2-14, n. 2). No seu estado atual, os conjuntos encontram-se encadernados com o fragmento asquenazita anteriormente mencionado, sob a mesma cota. Não obstante, os fragmentos pertenceram a manuscritos e épocas diferentes, conforme aponta a sua análise paleográfica: os fragmentos do Exxodo foram produzidos no século XIV; os fragmentos do Eclesiastes remetem-nos para o século XV. Estes últimos fragmentos encontram presença documentada em Portugal desde muito cedo, podendo ler-se neste documento uma breve nota escrita em português, datada de 1503, com a assinatura de um indivíduo chamado “António Nunes”.

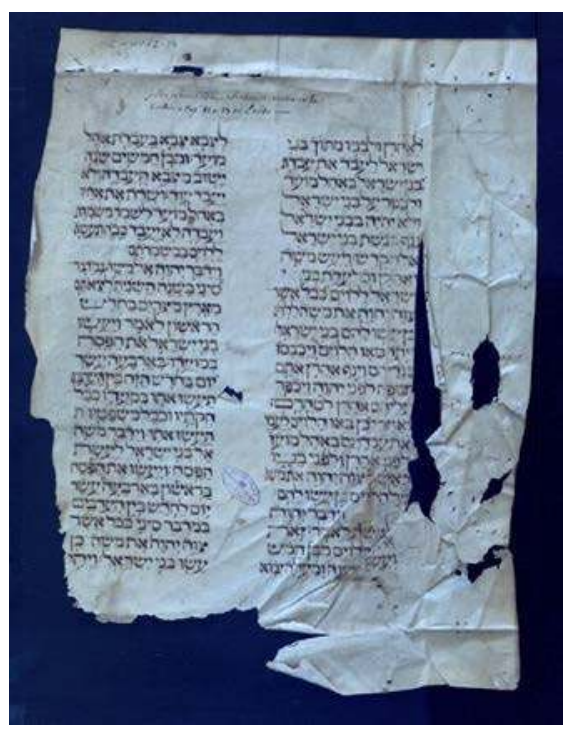

Figura 2 - Bíblia (fragmentos), Península Ibérica, século XIV. Évora, Biblioteca Pública de Évora, Cod. CXXV/2-14, n. 3, fol. 1r (permissão para reprodução obtida pelo autor do artigo em 02/03/2017). 
Para além dos núcleos até agora indicados, conservados em Coimbra e Évora, existem também fragmentos bíblicos hebraicos no Arquivo Nacional da Torre do Tombo, em Lisboa, e na Biblioteca Nacional de Portugal. Os fragmentos hebraicos que se conservam na Torre do Tombo foram identificados, na sua totalidade, por António Augusto Tavares ${ }^{10}$. Entre os documentos bíblicos, o Arquivo Nacional possui um fragmento do livro de Isaías $\left(40,2\right.$ - 44,16) (Documentos orientais, Mç. 1, n. 43) ${ }^{11}$, um fragmento do livro dos Números $\left(3,43\right.$ - 4,20) (Coleção de Cartas, Núcleo Antigo 891, Mç. 1, n. 96) ${ }^{12}$ e um fragmento do livro de Ester (2,17 - 5,5) (Livro n. 174, da Sé de Lamego). Os três conjuntos, provenientes de manuscritos diversos, encontram-se escritos com tipos paleográficos de letras quadradas sefarditas, vocalizadas, sendo o primeiro datável do século XIV e os restantes do século XV. Foram descobertos servindo de encadernação a manuscritos portugueses ${ }^{13}$, ou integram, ainda no presente, essas mesmas encadernações ${ }^{14}$.

Por fim, no campo dos manuscritos bíblicos importa referir ainda o conjunto de fragmentos hebraicos que se encontram na Biblioteca Nacional de Portugal (Cod. 13490), recém-descobertos no interior da encadernação de um incunábulo hebraico português (INC 1414-1415) ${ }^{15}$, por ocasião do seu restauro em $2010^{16}$. O documento, formando dois cadernos, contém uma parte do livro dos Salmos (Salmos 1 a 43), encontrando-se truncado no final. O texto foi escrito com caracteres hebraicos cursivizados tardios, de tipo bizantino, devendo a sua produção ter ocorrido no Médio Oriente (Iémen?), entre os séculos XVII e XVIII. A sua presença na encadernação do referido incunábulo sugere que o mesmo poderá ter-se encontrado, a dado momento, naquela área geográfica oriental, depois da sua saída do território português no final do século XV.

\footnotetext{
10 TAVARES, António Augusto - "Manuscritos hebraicos na Torre do Tombo". Didaskalia XI (1981), pp. 379-392.

${ }^{11}$ Disponível em http://digitarq.arquivos.pt/viewer?id=3908224

${ }^{12}$ Disponível em http://digitarq.arquivos.pt/viewer?id=3908275

${ }^{13}$ Por exemplo, o fragmento dos Números servia de empaste ao Núcleo Antigo, 572 - Livro dos Almazens d' El Rey na vila de Alcacere. Anno 1500.

${ }^{14}$ Como é o caso do fragmento de Ester que serve à encadernação de um livro intitulado Notas de Lopo Rodrigues anno de 1508. Lopo Rodrigues foi tesoureiro de D. Manuel I, sendo nomeado, em 1500, escrivão do campo das feiras da cidade da Guarda e de Trancoso (Chancelaria de D. Manuel I, liv. 12, fol. 18).

${ }^{15} \mathrm{O}$ incunábulo, em dois volumes, contém os Profetas Anteriores com Targum Jonatas e comentários de David Kimhi e Levi Gersonides. Foi impresso em Leiria, em 1494, na oficina de Samuel d'Ortas e filhos.

${ }^{16}$ Disponível em http://purl.pt/28993
} 


\section{Comentários bíblicos}

Enquanto as Bíblias constituem o principal núcleo de manuscritos hebraicos conservados nas bibliotecas e arquivos portugueses, os comentários bíblicos são pouco numerosos, preservando-se não mais que dois volumes em todo o país, um dos quais com enorme relevância para a história do movimento hebraísta cristão em Portugal no século XVI ${ }^{17}$. É o caso, com efeito, do Ms. Santa Cruz 63 que se encontra na Biblioteca Pública Municipal do Porto, com o Comentário ao Pentateuco de Abraão ibn Ezra (1089-1164) (figura 3) ${ }^{18}$. Copiado num tipo paleográfico de letra semicursiva italiana ${ }^{19}$, o volume terá sido produzido em Itália nos começos do século XIV. As circunstâncias da sua chegada a Portugal, no século XVI, e da sua entrada no Mosteiro de Santa Cruz de Coimbra, podem ser traçadas considerando a biografia do seu antigo proprietário, Manuel do Campo (†1571), que registou o seu nome, em hebraico, no volume. O perfil deste notável hebraísta português foi dado a conhecer por António Augusto Tavares, a partir da leitura de uma nota latina aposta por Frei Pedro, cónego do Mosteiro de Santa Cruz de Coimbra, no Ms. 475 da Biblioteca Pública Municipal do Porto, com exercícios e gramáticas em línguas orientais ${ }^{20}$. De acordo com este informe, Manuel do Campo, nascido em Eira Pedrinha, junto de Farinha-Podre (perto de Coimbra), viveu em Roma, onde era apreciado pelos seus conhecimentos, gozando da amizade do Papa Leão X. Faleceu na Cidade Eterna em 1521. Depois da sua morte, a livraria que possuía foi entregue aos seus parentes de Eira Pedrinha, sendo adquirida mais tarde pelo reformador da Ordem de Santa Cruz, D. Frei Brás de Barros (1500-1559), por volta de 1528. O comentario de Abraão ibn Ezra encontrar-se-ia seguramente entre o lote de manuscritos adquiridos pelo Mosteiro de Santa Cruz à família de Manuel do Campo, o qual provavelmente comprou o volume nos anos em que residiu em Itália.

\footnotetext{
17 Sobre este movimento, veja-se PINTO, Porfírio - "Portugal e o movimento hebraísta cristão quinhentista". Cadernos de Estudos Sefarditas 14 (2015), pp. 203-224.

${ }^{18}$ NASCIMENTO, Aires Augusto; MEIRINHOS, José - Catálogo dos Códices da Livraria de Mão do Mosteiro de Santa Cruz de Coimbra na Biblioteca Pública Municipal do Porto. Porto: Biblioteca Pública Municipal do Porto, 1997, pp. 285-287.

${ }^{19}$ Os títulos das perícopes bíblicas comentadas encontram-se escritos com caracteres quadrados, também italianos, assim se distinguindo dos comentários propriamente ditos.

${ }^{20}$ Sobre este manuscrito, proveniente do Mosteiro de Santa Cruz de Coimbra, datado do século XVI, veja-se TAVARES, António Augusto - "Línguas orientais num manuscrito português do século XVI". Didaskalia III (1973), pp. 157-180 (especialmente pp. 159-160 e p. 162, nota 6).
} 


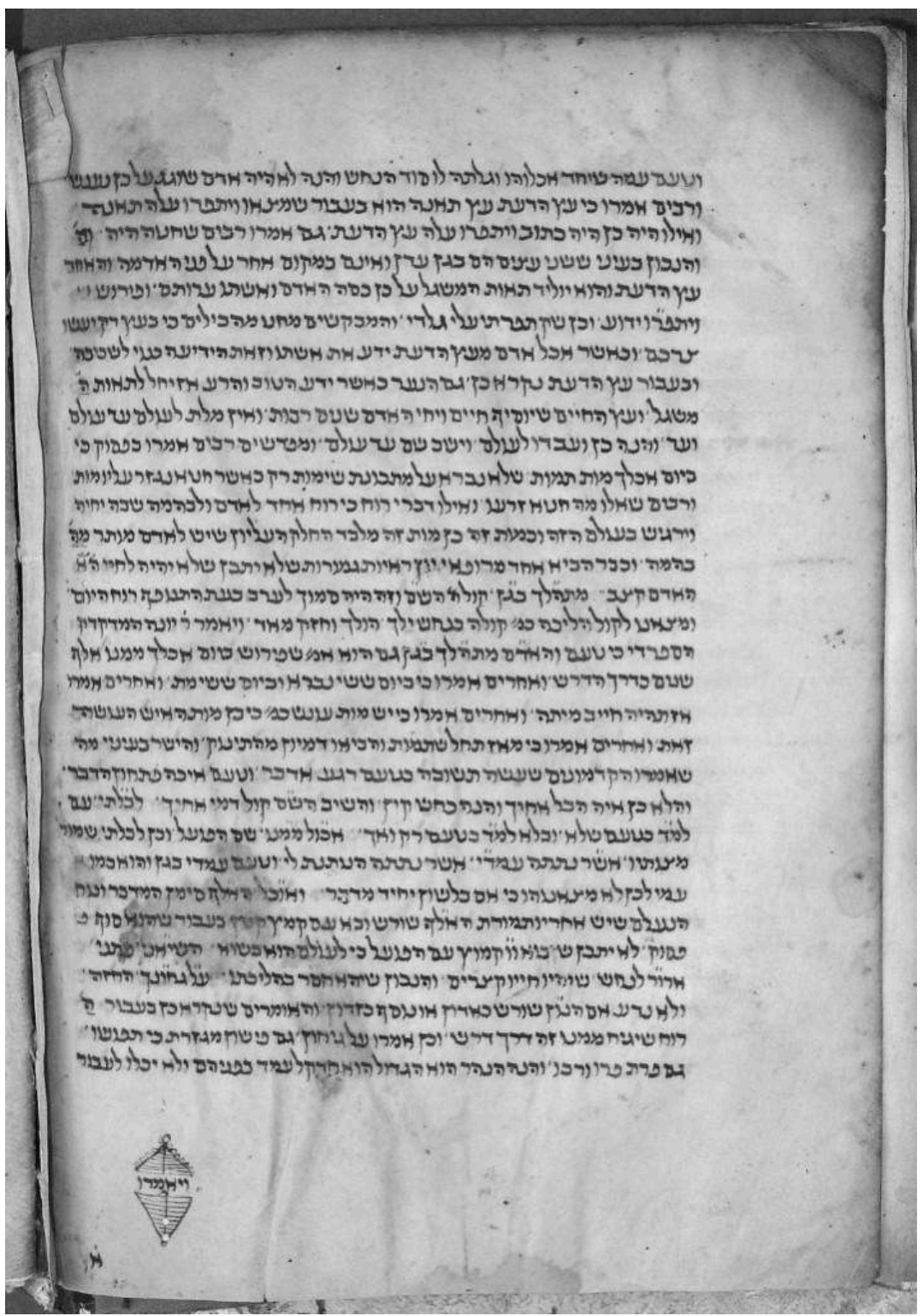

Figura 3 - Comentário ao Pentateuco de Abraão ibn Ezra, Itália, século XIV. Porto, Biblioteca Pública Municipal do Porto, Ms. Santa Cruz 63, fol. 7v (permissão para reprodução obtida pelo autor do artigo em 06/03/2017).

De grande interesse, mas envolto em mistérios, constitui também o comentário bíblico conservado na Biblioteca Nacional de Portugal (Cod. 11676). De proveniência desconhecida, mas realizado no decurso do século XVI, o volume contém Comentários a Isaías, Jeremias e Ezequiel, de autoria ainda não plenamente esclarecida. Com efeito, o título que encabeça o livro - "Interpretação bela sobre Isaías, Jeremias e Ezequiel. Escreveu-a e estabeleceu-a o sábio rabi Abraão bar David bar Ezra, o sefardi" - aponta mais dificuldades do que certezas quanto à identificação do autor, não sendo conhecida 
a identidade deste sábio entre as autoridades rabínicas do tempo ${ }^{21}$. Em todo o caso, os comentários ao profeta Isaías pertencem ao rabi Isaías de Trani ${ }^{22}$, autoridade rabínica italiana do século XIII, sendo ainda necessário confirmar a autoria dos restantes textos. Perante estes dados, poderá Abraão bar David bar Ezra, o sefardi, corresponder ao copista do manuscrito, e não ao autor dos comentários? O apodo com que este indivíduo é apresentado - "o sefardi" - sugere que Abraão está relacionado com a Península Ibérica, onde, contudo, não se encontra, pois o uso da expressão não teria qualquer sentido no interior da Península. O texto deste comentario foi copiado num tipo paleográfico de letras quadradas sefarditas, confirmando a pertença, ou a formação, do seu escriba na área geocultural sefardita. Em suma, o volume carece de uma investigação aprofundada dos comentários que não caberia neste estudo, investigação tanto mais necessária quanto se ignora quase tudo em relação à sua autoria e às circunstâncias da sua produção e aquisição.

\section{Textos legais}

Neste domínio assinalamos a presença de fragmentos do Talmud babilonense, verdadeira enciclopédia de direito religioso hebraico, tanto no Arquivo Nacional da Torre do Tombo, em Lisboa (Corpo Cronológico, Parte III, Mç. 1, n. 4) ${ }^{23}$ como na Biblioteca Pública de Évora (Cod. CXXIV/2-47d, n. 1) (figura 4) ${ }^{24}$.

\footnotetext{
${ }^{21} \mathrm{O}$ desconforto causado por este nome levou alguns investigadores recentes a confundir a identidade de Abraão bar David bar Ezra, o sefardi, com o famoso rabino Abraão ben Meir ibn Ezra (1089-1164), cujos comentários não são os que se encontram no manuscrito. MUCZNIK, Lúcia Liba - Judaica. Nas coleções da Biblioteca Nacional de Portugal..., p. 17, n. 2.

${ }^{22}$ Conforme se pode confirmar pelo confronto entre o texto deste manuscrito e os comentários de Isaías de Trani, em COHEN, Menahem (ed.) - Mikraot Gedolot haKeter. Vol. 4: Isaiah. A Revised and Augmented Scientific Edition. Ramat Gan: Bar-Ilan University Press, 1996.

${ }^{23}$ TAVARES, António Augusto - "Manuscritos hebraicos na Torre do Tombo"..., pp. 389-392.

${ }^{24}$ RIVARA, Heliadoro da Cunha; MATOS, Joaquim António Telles de - Catalogo dos Manuscritos da Bibliotheca Publica Eborense. tomo IV. Lisboa: Imprensa Nacional, 1871, p. 71.
} 


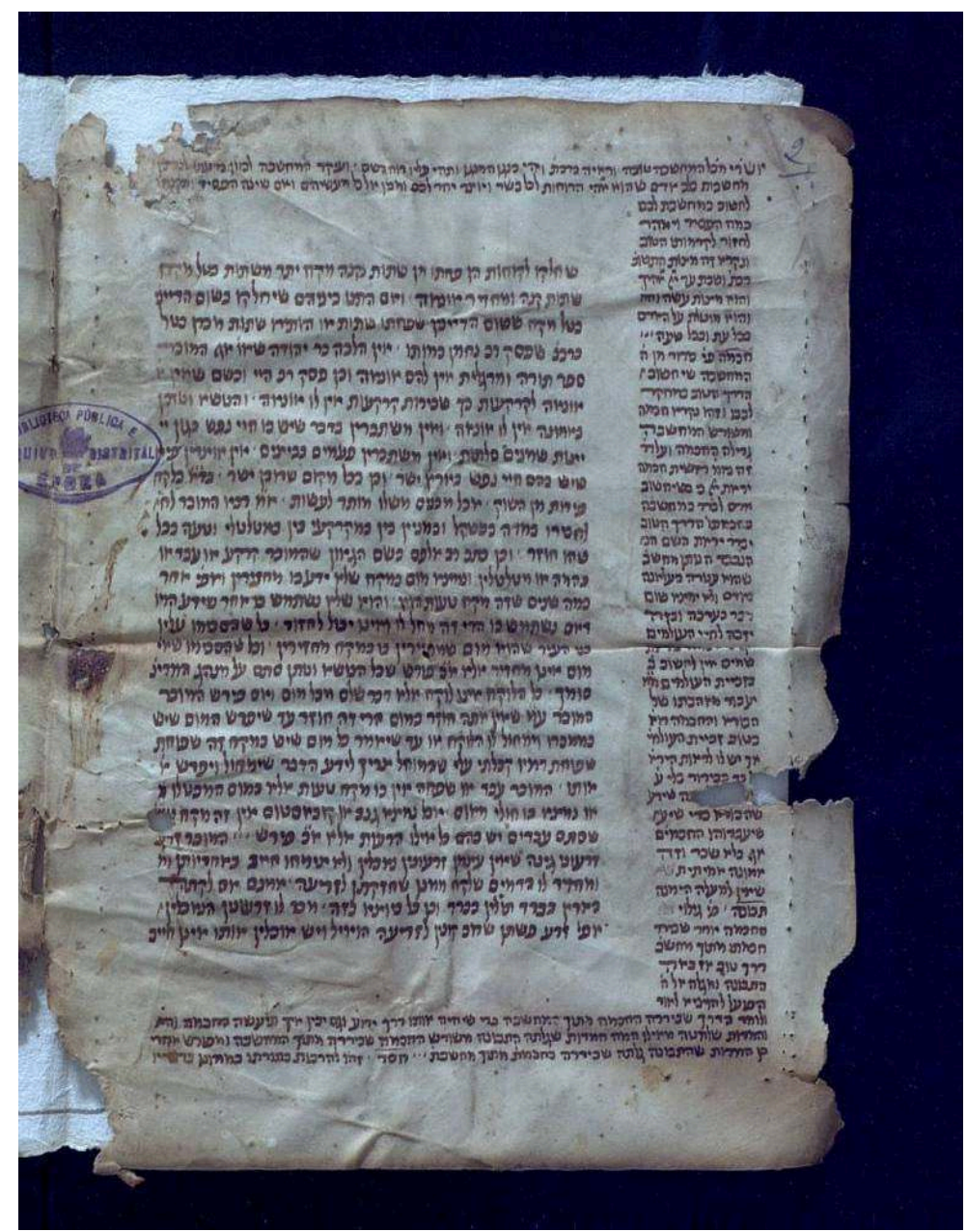

Figura 4 - Talmud (fragmentos), Alemanha, século XIV. Évora, Biblioteca Pública de Évora, Cod. CXXIV/2-47d, n. 1, fol. 1v (permissão para reprodução obtida pelo autor do artigo em 02/03/2017).

Os fragmentos lisboetas, muito mutilados, representam partes do sexto capítulo do tratado de Pesahim, que é o terceiro do Seder Moed (= Ordem do Tempo), tratado que apresenta as orientações e prescrições relativas à observância da Páscoa. No caso concreto, os fragmentos referem-se às instruções relativas ao sacrifício que "empurra o sábado se calhar na Páscoa". Escritos com caracteres paleográficos quadrados sefarditas, os documentos foram produzidos na Península Ibérica (Portugal?) no século $\mathrm{XV}$, tendo sido encontrados a servir de capa a um volume com "vários capítulos do modo com que se devem arrecadar as cizas do sal”, redigidos nos finais do século XIV, embora a encadernação seja posterior ${ }^{25}$.

\footnotetext{
${ }^{25} \mathrm{O}$ manuscrito contém duas cartas em português, uma relacionada com a imposição do sal e outra com privilégios concedidos aos moradores de Elvas, entre os quais o de terem cavalos.
} 
No que se refere aos fragmentos talmúdicos eborenses, os documentos contêm partes do segundo capítulo do tratado do Shabat, que é o primeiro do Seder Moed, tratado que indica as leis relativas ao sábado, dia de descanso semanal. O texto dos fragmentos, com a Gemara nas margens, reflete sobre as lâmpadas que se acendem ao sábado. Escrito num tipo paleográfico de letras quadradas asquenazitas, foi realizado provavelmente em território alemão nos finais do século XIV, sendo descoberto na encadernação de um livro não-identificado.

\section{Oração e poesia litúrgica}

Embora os livros de oração se encontrem, depois da Bíblia, entre os mais populares e necessários à vida religiosa judaica, nas bibliotecas portuguesas não encontramos mais do que um exemplar que se enquadra nesta tipologia. Referimo-nos a um mahzor com coleções de poemas penitenciais destinados à liturgia da festividade do 9 do mês de $a v$ (Tish'a be-'av), um tempo litúrgico no qual se rememora a destruição do Templo de Jerusalém e outros eventos dramáticos da história do povo hebreu disperso. $\mathrm{O}$ volume foi desmembrado em três partes distintas, encontrando-se duas partes em Portugal, a primeira e a terceira parte (a primeira parte encontra-se na Biblioteca Nacional, Ms. Iluminado $3^{26}$, e a terceira parte na Biblioteca Pública de Évora, Cod. CXXIV/2-47d, n. 3) (figura 5); uma outra parte encontra-se em Inglaterra, a parte intermédia (Londres, British Library, Ms. Add. 20747) ${ }^{27}$. Os três núcleos de fragmentos apresentam características codicológicas semelhantes, com formato oblongo e dimensões aproximadas, bem como numeração sequencial dos poemas entre as partes. Para além das lamentações dedicadas ao Templo, o volume contém diversos poemas com alusões às perseguições, destruições e martírios sofridos pelos judeus nos reinos de Castela e de Aragão nos finais do século XIV e começos do século XV. O texto foi escrito com caracteres paleográficos quadrados, de tipo sefardita, tendo sido produzido na Península

\footnotetext{
${ }^{26}$ Sobre o Iluminado 3 da Biblioteca Nacional de Portugal, veja-se MOITA, Tiago - "18. Tikun leil tet be-av". in AFONSO, Luís Urbano; MIRANDA, Adelaide (ed.) - O livro e a iluminura judaica em Portugal no final da Idade Média. Lisboa: BNP, 2015, pp. 145-146. O manuscrito encontra-se disponível em http://purl.pt/24884

${ }^{27}$ Sobre o Ms. Add. 20747 da British Library, veja-se MARGOLIOUTH, George - Catalogue of the Hebrew and Samaritan Manuscripts in the British Museum. vol. II. Londres: British Museum, 1905, n. 695.
} 
Ibérica, na segunda metade do século XV. O seu pequeno tamanho e as indicações de caráter litúrgico no início de alguns poemas sugerem o seu manuseio na sinagoga.

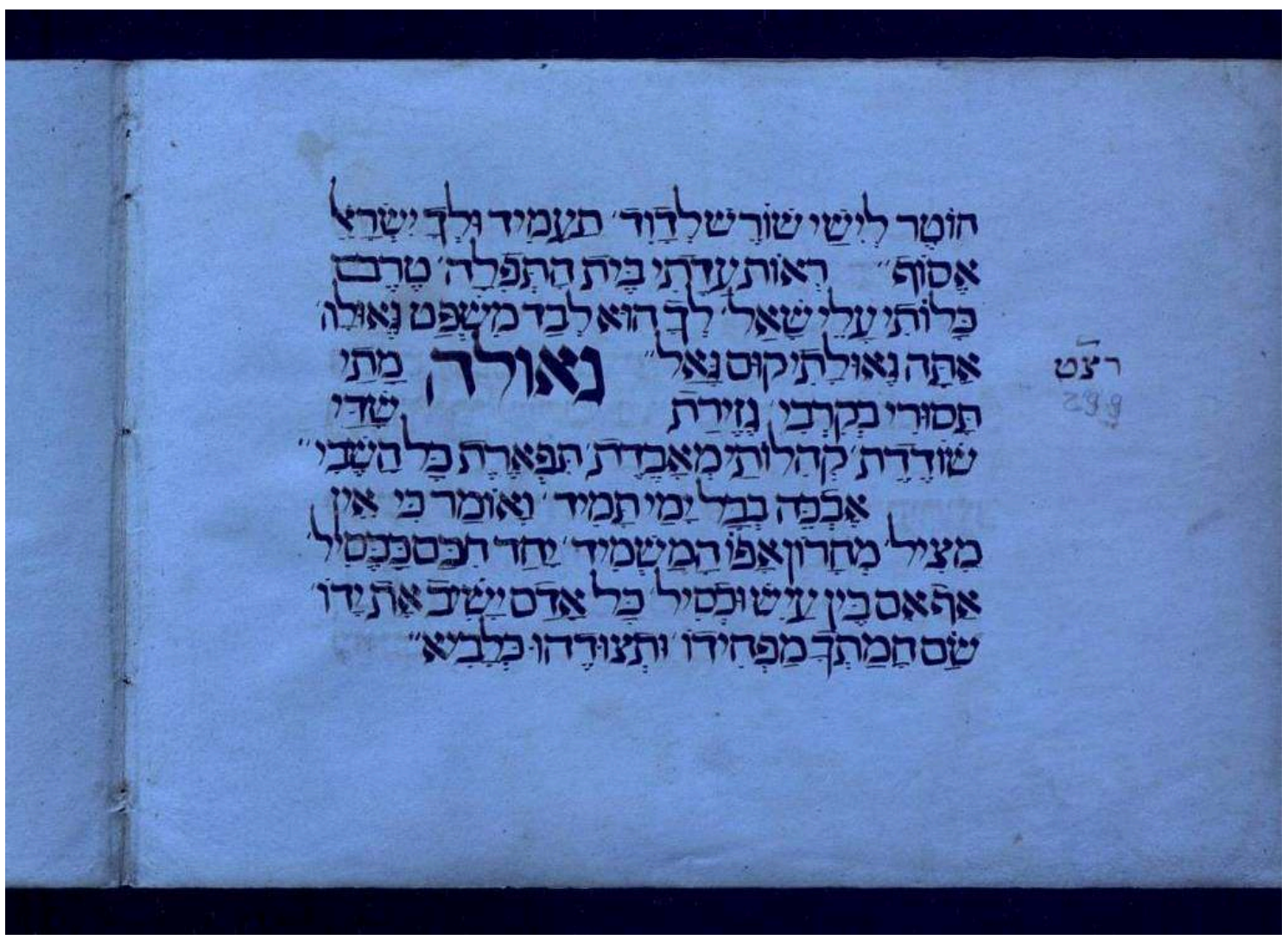

Figura 5 - Mahzor (fragmentos), Península Ibérica, século XV. Évora, Biblioteca Pública de Évora, Cod. CXXIV/2-47d, n. 3, fol. 1v (permissão para reprodução obtida pelo autor do artigo em 02/03/2017).

O inteiro maḥzor foi adquirido por Frei Manuel do Cenáculo (1724-1814), no período em que governou a diocese de Beja (1770-1802), ou anterior. Com efeito, por indicação existente na encadernação do Iluminado 3 , esta parte do manuscrito foi oferecida a António Ribeiro dos Santos por Frei Manuel do Cenáculo, então bispo de Beja. O volume deverá ter sido desmembrado em partes distintas neste período, permanecendo uma parte com António Ribeiro dos Santos (que a deixa à Biblioteca Nacional) e outra parte com Frei Manuel do Cenáculo (que a deixa à Biblioteca Pública de Évora). O Ms. Add. 20747 da British Library foi adquirido em 1852 pelo British Museum ao livreiro Adolphus Asher (1800-1853), em Berlim, conforme inscrição aposta no volume. 


\section{Gramáticas}

A Biblioteca Pública Municipal do Porto conserva no Ms. 98 uma gramática hebraica contendo o Sefer Mikhlol de David Kimhi (c. 1160-c. 1235), texto que incide nos verbos hebraicos e nas regras que presidem à sua conjugação (figura 6). O manuscrito foi copiado num tipo paleográfico de letras semicursivas sefarditas, tendo a sua produção ocorrido na Península Ibérica, nos começos do século XV. Sem cólofon nem outras anotações não é possível concretizar com detalhe o percurso deste volume, ao menos até ao ano de 1879, quando é referido no fascículo 1 do Indice Preparatorio do catalogo dos manuscriptos da Biblioteca Pública Municipal do Porto, devendo a sua aquisição ter ocorrido em momento anterior ${ }^{28}$.

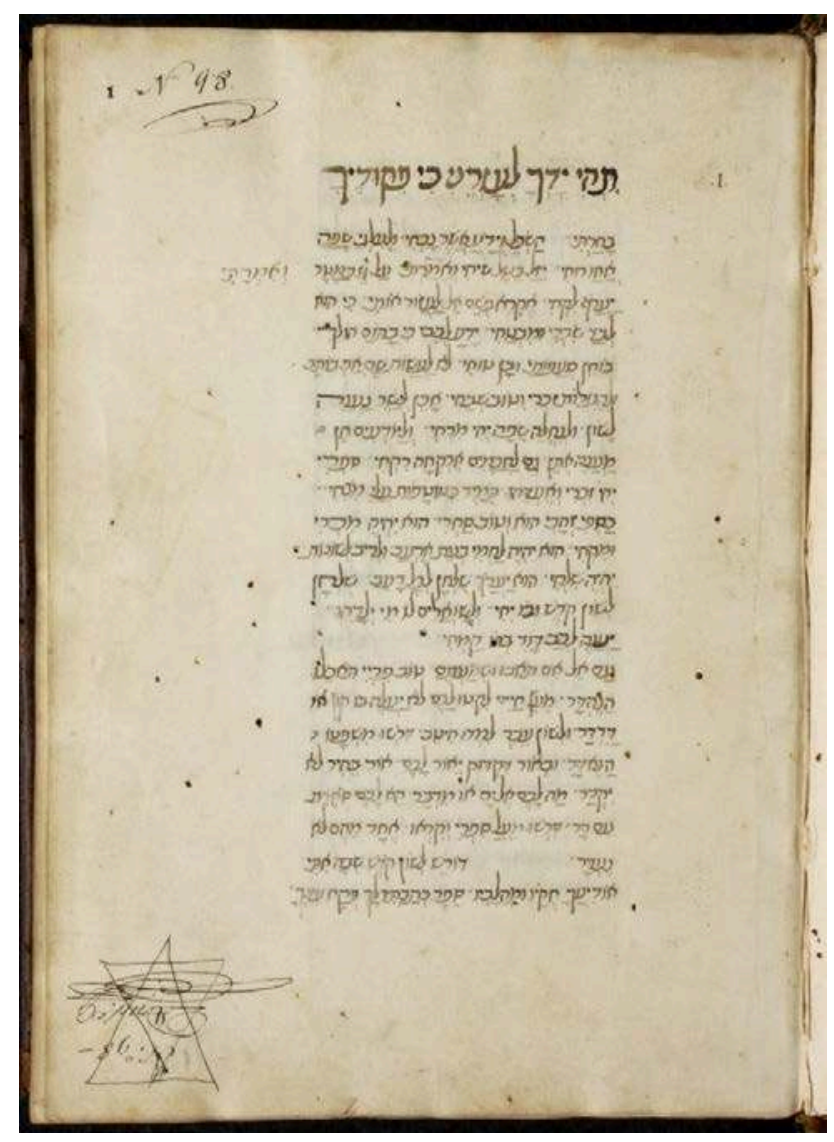

Figura 6 - Sefer Mikhlol de David Kimhi, Península Ibérica, século XV. Porto, Biblioteca Pública Municipal do Porto, Ms. 98, fol. 1r (permissão para reprodução obtida pelo autor do artigo em 06/03/2017).

28 INDICE preparatorio do catalogo dos manuscriptos, com repertorio alphabetico dos auctores, assumptos e principaes topicos n'elles existentes. fasc. 1: Mss. membranaceos (Catalogo da Bibliotheca Publica Municipal do Porto). Porto: Bibliotheca Publica Municipal do Porto, 1879, p. 62 (n. 130). 


\section{Misticismo e Cabala}

No que se refere a este tópico assinalamos a presença na Biblioteca Pública Municipal do Porto de um exemplar do Zohar, um dos trabalhos mais importantes da Cabala, no misticismo judaico, com interpretações místicas sobre o Pentateuco. O manuscrito em apreço contém apenas os comentários ao Génesis (Ms. 105) (figura 7). Encontra-se escrito com caracteres semicursivos hebraicos, de tipo italiano (com títulos e palavras iniciais em escrita quadrada de módulo maior), área geocultural onde o volume terá sido produzido, na segunda metade do século XV. Embora o códice apresente ao começo assinaturas de dois censores eclesiásticos, nomeadamente, de António Gonçalves (assina duas vezes) e de Frei Bernardo (assina quatro vezes), ambas sem indicação de data e lugar, nada mais se conhece do percurso histórico deste manuscrito até à sua referência no fascículo 1 do Indice Preparatorio do catalogo dos manuscriptos da Biblioteca Pública Municipal do Porto, em 1879, ocorrendo a sua aquisição em momento anterior ${ }^{29}$.

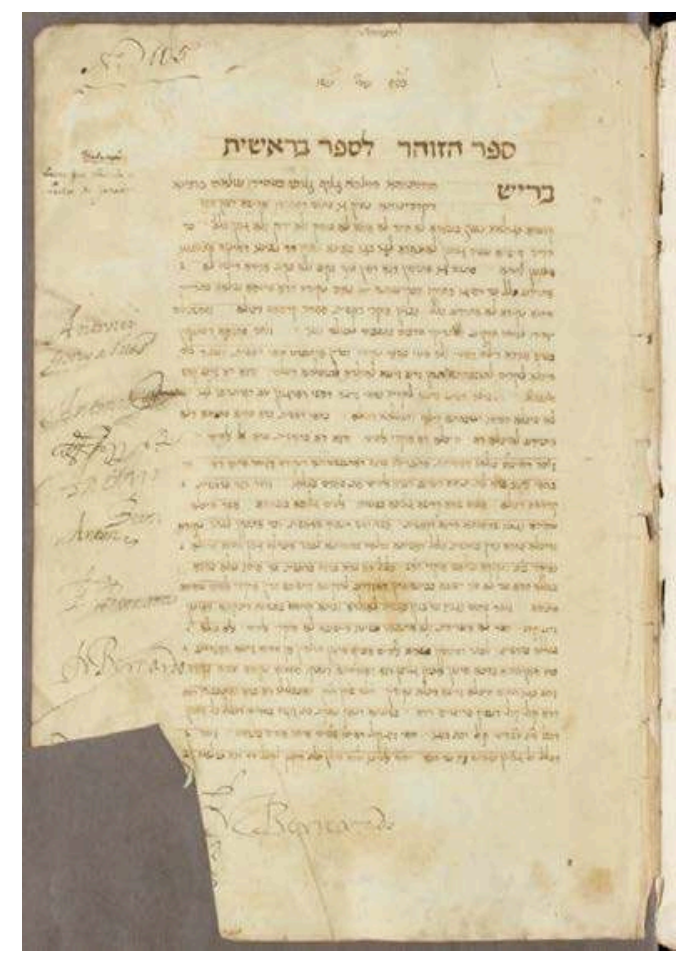

Figura 7 - Zohar, Itália, século XV. Porto, Biblioteca Pública Municipal do Porto, Ms. 105, fol. 1r (permissão para reprodução obtida pelo autor do artigo em 06/03/2017).

\footnotetext{
${ }^{29}$ INDICE preparatorio do catalogo dos manuscriptos..., p. 64 (n. 134).
} 


\section{Ciência}

Os manuscritos hebraicos com obras de ciência existentes nas bibliotecas portuguesas compreendem somente textos de medicina. Na Biblioteca Pública Municipal do Porto encontramos o Tesoro de los Proves (Thesaurus pauperum) de Pedro Hispano, escrito em castelhano com caracteres hebraicos (aljamiado) (MS-FA-14) ${ }^{30}$. O volume, com cópia provável nos finais do século XV ou inícios do século XVI, integrava a coleção de Francisco Lopes de Azevedo Velho da Fonseca (1809-1876), primeiro conde de Azevedo, que o legou à biblioteca portuense em 1871.

Para além deste manuscrito, os restantes documentos hebraicos com textos médicos conservados em bibliotecas portuguesas encontram-se em estado fragmentário, todos na Biblioteca do Paço Ducal, em Vila Viçosa ${ }^{31}$. Os vários fragmentos, descobertos por D. Manuel II (1889-1932) na encadernação de um livro da sua biblioteca, encontram-se dispostos em três maços distintos, formando um único volume intitulado Hebrew medical scientific mss. 15 century found in the covers of Portuguese book (Vol. XIV). A identificação do conteúdo do primeiro maço de fragmentos deve-se a Anne-Sylvie Guénoun, que reconheceu neste texto partes do comentário de Gerardus de Solo ao Livro IX do Almansor, de Rhazes, na versão hebraica de Léon Joseph de Carcassonne ${ }^{32}$. O documento apresenta o cólofon do escriba, assinalando a conclusão da cópia na cidade de Fromista, no reino de Castela, em 1489. O volume deverá ter sido trazido para Portugal por um indivíduo judeu, provavelmente médico, depois da expulsão dos reinos de Castela e de Aragão, em 1492.

\footnotetext{
${ }^{30} \mathrm{O}$ texto do manuscrito encontra-se integralmente transcrito e editado por Maria Adélia Soares de Carvalho Mendes: PEDRO HISPANO, Tesoro de proves. Versão em judeu-castelhano aljamiado (séc. XV). Mediaevalia, Textos e estudos. Introdução, edição e índices por Maria Adélia Soares de Carvalho Mendes. Porto: Fundação Eng. António de Almeida, 1999. Sobre este manuscrito, veja-se, ainda MEIRINHOS, José Francisco - Bibliotheca manuscripta Petri Hispani. Os manuscritos das obras atribuídas a Pedro Hispano. Lisboa: Fundação Calouste Gulbenkian / Fundação para a Ciência e Tecnologia, 2011, p. 352.

${ }^{31}$ MOITA, Tiago - "Tratados Médicos dos Judeus em Portugal no século XV. Análise do núcleo de fragmentos hebraicos do tratado de Gerardus de Solo da Biblioteca do Paço Ducal de Vila Viçosa". in First International Conference "Jewish Heritage - Science, Culture, Knowledge”. Proceedings. Tomar: Instituto Politécnico de Tomar (publicação eletrónica em CD).

${ }^{32}$ GUÉNOUN, Anne Sylvie - "Les traductions en hébreu de l'oeuvre du médecin Gérard de Solo (XIV siècle)". Revue des Études juives 164/3-4 (2005), p. 482.
} 
Os restantes maços de fragmentos hebraicos existentes no volume do Paço Ducal contêm textos de autor diverso do primeiro maço, nomeadamente, passagens do Cânon de Medicina de Avicena, um dos mais importantes e influentes livros médicos entre os judeus na Idade Média, e também um dos mais traduzidos ${ }^{33}$. O primeiro maço inclui capítulos do Cânon relativos à secção sobre o pulso; o segundo maço compreende capítulos concernentes à secção das estações (com discussões sobre as condições adequadas para a habitação, considerando a direção do vento e outras questões meteorológicas).

\section{Conclusão}

Embora pouco expressivos em número, os manuscritos hebraicos existentes nas bibliotecas públicas e arquivos estatais portugueses constituem um rico património insuficientemente conhecido e estudado. Não obstante o número limitado de remanescentes, o conteúdo dos exemplares é muito diverso, revestindo-se de particular importância os manuscritos bíblicos, alguns entre os mais sumptuosos códices iluminados no contexto da arte hebraica medieval. De grande interesse e significado cultural constituem os códices trazidos para Portugal por hebraístas cristãos no século XVI, bem como os variadíssimos fragmentos hebraicos encontrados nas pastas de manuscritos portugueses e latinos, ou mesmo na encadernação de um incunábulo hebraico, com conteúdos bíblicos, talmúdicos ou científicos. Com base na tipologia de escrita destes documentos, alguns exemplares apresentam uma produção não peninsular; a maioria dos fragmentos, porém, foi produzida na Península Ibérica, não sendo possível afirmar com segurança, na ausência de cólofon, uma produção diretamente portuguesa $^{34}$.

Importa referir aqui a existência de um conjunto de fragmentos hebraicos acerca dos quais pouco posso afirmar nas condições atuais da sua preservação. Estes fragmentos, disponíveis na Torre do Tombo, com texto em escrita cursiva sefardita, do século XV, integram a encadernação do Livro n. 175 da Sé de Lamego. O péssimo estado de

\footnotetext{
${ }^{33}$ FERRE, Lola - “Avicena Hebraico: la traducción del Canon de Medicina”. Miscelánea de Estudios Árabes y Hebraicos 52 (2003), pp. 163-182.

34 Com efeito, alguns manuscritos foram trazidos para Portugal por judeus vindos de outros reinos peninsulares, como bem comprova os fragmentos de Vila Viçosa.
} 
conservação dos fragmentos no interior da encadernação, que os mantém severamente apertados entre si, impede-me por agora a sua leitura, descrição e identificação.

Para concluir, gostaria de referir ainda a existência de fragmentos hebraicos sefarditas medievais em coleções particulares, tanto em Lisboa como em Viseu, cuja análise não caberia neste trabalho, focado nas bibliotecas públicas e arquivos nacionais. A sua identificação e estudo foram realizados em outro momento pelo saudoso hebraísta português António Augusto Tavares ${ }^{35}$.

\section{Referências bibliográficas:}

\section{Fontes manuscritas}

Coimbra, Biblioteca Geral da Universidade de Coimbra, Caixa B 12

Coimbra, Biblioteca Geral da Universidade de Coimbra, Cofre 1

Évora, Biblioteca Pública de Évora, Cod. CXXIV/2-47d

Évora, Biblioteca Pública de Évora, Cod. CXXIV/2-48d

Évora, Biblioteca Pública de Évora, Cod. CXXV/2-14

Évora, Biblioteca Pública de Évora, Gaveta 8

Lisboa, Biblioteca Nacional de Portugal, Iluminado 72

Lisboa, Biblioteca Nacional de Portugal, Iluminado 3

Lisboa, Biblioteca Nacional de Portugal, Cod. 13490

\footnotetext{
35 TAVARES, António Augusto - "Manuscrito hebraico e aramaico em Lisboa". Didaskalia VIII (1978), pp. 187-194. TAVARES, António Augusto - "Novos manuscritos hebraicos". Didaskalia XXV (1995), pp. 189-194. Desconhecemos o paradeiro atual do fragmento de Lisboa, com texto bíblico. Os fragmentos de Viseu, com textos filosóficos, comentários bíblicos e um tratado de medicina, encontram-se na posse do padre José Fernandes Vieira, sacerdote da diocese de Viseu.
} 
Lisboa, Biblioteca Nacional de Portugal, Cod. 11676

Lisboa, Biblioteca Nacional de Portugal, Ms. 256, n. 43

Lisboa, Torre do Tombo, Chancelaria de D. Manuel I, liv. 12, fol. 18

Lisboa, Torre do Tombo, Coleção de Cartas, Núcleo Antigo 891, Mç. 1, n. 43

Lisboa, Torre do Tombo, Coleção de Cartas, Núcleo Antigo 891, Mç. 1, n. 96

Lisboa, Torre do Tombo, Corpo Cronológico, Parte III, Mç. 1, n. 4

Lisboa, Torre do Tombo, Livro da Sé de Lamego n. 174

Lisboa, Torre do Tombo, Livro da Sé de Lamego n. 175

Londres, British Library, Ms. Add. 20747

Ponta Delgada, Biblioteca Pública e Arquivo Distrital de Ponta Delgada, Cofre 270 Res

Porto, Biblioteca Pública Municipal, Ms. Santa Cruz 63

Porto, Biblioteca Pública Municipal, MS-FA-14

Porto, Biblioteca Pública Municipal, Ms. 98

Porto, Biblioteca Pública Municipal, Ms. 105

Vila Viçosa, Biblioteca do Paço Ducal, Volume XIV

\section{Fontes impressas}

Lisboa, Biblioteca Nacional de Portugal, INC 1414-1415

\section{Estudos}

AFONSO, Luís Urbano; MOITA, Tiago; MATOS, Débora - "La Biblia de Coimbra y la «Escuela Andaluza» de iluminacíon hebraica". Archivo Español de Arte 88/349 (2015), pp. 53-68.

BALleStEROS, Carmen - "Mezuzah da Biblioteca Pública de Évora”. A Cidade de Évora: Boletim de Cultura da Câmara Municipal (2a Série) 2 (1996), pp. 285-296. 
CARREIRA, José Nunes - "Torá de Rabo de Peixe". Cadmo. Revista do Instituto Oriental da Universidade de Lisboa 4-5 (1995), pp. 205-208.

COHEN, Menahem (ed.) - Mikraot Gedolot haKeter. Vol. 4: Isaiah. A Revised and Augmented Scientific Edition. Ramat Gan: Bar-Ilan University Press, 1996.

COIMBRA JUDAICA - Actas. Coimbra: Câmara Municipal de Coimbra, 2009.

DEL BARCO, Javier; SANTOS, Inacio Panizo - "Fragmentos de incunables hebreos en documentos inquisitoriales del Tribunal de Calahorra-Logroño". Huarte de San Juan. Geografía e Historia 17 (2010), pp 295-308.

FERRE, Lola - "Avicena Hebraico: la traducción del Canon de Medicina". Miscelánea de Estudios Árabes y Hebraicos 52 (2003), pp. 163-182.

GUÉNOUN, Anne Sylvie - "Les traductions en hébreu de l'oeuvre du médecin Gérard de Solo (XIV siècle)". Revue des Études juives 164/3-4 (2005), pp. 463-488.

INDICE preparatorio do catalogo dos manuscriptos, com repertorio alphabetico dos auctores, assumptos e principaes topicos n'elles existentes. fasc. 1: Mss. membranaceos (Catalogo da Bibliotheca Publica Municipal do Porto). Porto: Bibliotheca Publica Municipal do Porto, 1879.

LEHNARDT, Andreas - "Genizat Germania" - Hebrew and Aramaic Binding Fragments from Germany in Context. Leiden-Boston: Brill, 2010.

MARGOLIOUTH, George - Catalogue of the Hebrew and Samaritan Manuscripts in the British Museum. 4 vols. Londres: British Museum, 1905.

MEIRINHOS, José Francisco - Bibliotheca manuscripta Petri Hispani. Os manuscritos das obras atribuídas a Pedro Hispano. Lisboa: Fundação Calouste Gulbenkian / Fundação para a Ciência e Tecnologia, 2011. 
MOITA, Tiago - "O livro hebraico português medieval: uma história de sobrevivência". in AFONSO, Luís Urbano; MIRANDA, Adelaide (ed.) - O livro e a iluminura judaica em Portugal no final da Idade Média. Lisboa: BNP, 2015, pp. 67-77.

- “18. Tikun leil tet be-av”. in AFONSO, Luís Urbano; MIRANDA, Adelaide (ed.) - $O$ livro e a iluminura judaica em Portugal no final da Idade Média. Lisboa: BNP, 2015, pp. 145-146.

- O livro hebraico português na Idade Média. Do Sefer he-Aruk de Seia (1284-85) aos manuscritos iluminados tardo-medievais da Escola de Lisboa e aos primeiros incunábulos. Lisboa: Faculdade de Letras da Universidade de Lisboa, 2017. Tese de Doutoramento.

- "Tratados Médicos dos Judeus em Portugal no século XV. Análise do núcleo de fragmentos hebraicos do tratado de Gerardus de Solo da Biblioteca do Paço Ducal de Vila Viçosa". in First International Conference "Jewish Heritage - Science, Culture, Knowledge”. Proceedings. Tomar: Instituto Politécnico de Tomar (publicação eletrónica em CD), 2012.

MUCZNIK, Lúcia Liba - Judaica. Nas coleções da Biblioteca Nacional de Portugal, Séculos XIII a XVIII. Lisboa: BNP, 2014.

NASCIMENTO, Aires Augusto; MEIRINHOS, José - Catálogo dos Códices da Livraria de Mão do Mosteiro de Santa Cruz de Coimbra na Biblioteca Pública Municipal do Porto. Porto: Biblioteca Pública Municipal do Porto, 1997.

PEDRO HISPANO, Tesoro de proves. Versão em judeu-castelhano aljamiado (séc. XV). Mediaevalia, Textos e estudos. Introdução, edição e índices por Maria Adélia Soares de Carvalho Mendes. Porto: Fundação Eng. António de Almeida, 1999.

PERANI, Mauro - "Morte e rinascita dei manoscritti ebraici: il loro riuso come legature e la loro recente riscoperta". in CANETTI, Luigi; CAROLI, Martina; MORINI, Enrico; 
SAVIGNI, Raffaelle (ed.) - Studi di storia del cristianesimo. Per Alba Maria Orselli. Ravena: Longo Angelo, 2008, pp. 313-336.

PINTO, Porfírio - "Portugal e o movimento hebraísta cristão quinhentista". Cadernos de Estudos Sefarditas 14 (2015), pp. 203-224.

RAMOS, José Augusto; AFONSO, Luís Urbano; MOITA, Tiago - "A Bíblia de Cervera: um manuscrito sefardita iluminado?". Cadernos de Estudos Sefarditas 14 (2015), pp. 171-202.

RIVARA, Heliadoro da Cunha; MATOS, Joaquim António Telles de - Catalogo dos Manuscritos da Bibliotheca Publica Eborense, tomo IV. Lisboa: Imprensa Nacional, 1871.

SIDARUS, Adel - "Manuscritos árabes em Portugal". Estudos Orientais 2. Lisboa: Instituto Oriental, 1991, pp. 117-126.

SOALHEIRO, João - “124. Mezuzah”. in AZEVEDO, Carlos A. Moreira (coord.) Cristo, Fonte de Esperança (Catálogo da Exposição). Porto: Diocese do Porto, 2000, p. 216.

TAVARES, António Augusto - "Línguas orientais num manuscrito português do século XVI". Didaskalia III (1973), pp. 157-180.

- “Manuscrito hebraico e aramaico em Lisboa". Didaskalia VIII (1978), pp. 187-194.

- “Manuscritos hebraicos na Torre do Tombo". Didaskalia XI (1981), pp. 379-392.

- “Novos manuscritos hebraicos”. Didaskalia XXV (1995), pp. 189-194. 


\section{COMO CITAR ESTE ARTIGO}

\section{Referência electrónica:}

MOITA, Tiago - "Manuscritos hebraicos em Portugal". Medievalista 22 (JulhoDezembro 2017). [Em linha] [Consultado dd.mm.aaaa]. Disponível em http://www2.fcsh.unl.pt/iem/medievalista/MEDIEVALISTA22/moita2206.html ISSN 1646-740X.

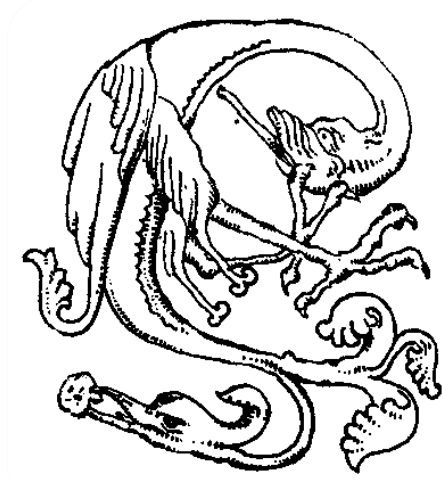

